\title{
Relationship between the Sensory-Determined Astringency and the Flavanolic Composition of Red Wines
}

\author{
Natalia Quijada-Morín, ${ }^{\dagger}$ Jorge Regueiro, ${ }^{\ddagger}$ Jesús Simal-Gándara, ${ }^{\ddagger}$ Esperanza Tomás, ${ }^{\S}$ \\ Julián C. Rivas-Gonzalo, ${ }^{\dagger}$ and M. Teresa Escribano-Bailón ${ }^{\dagger}{ }^{\dagger}$ \\ ${ }^{\dagger}$ Grupo de Investigación en Polifenoles, Universidad de Salamanca, E-37007 Salamanca, Spain \\ ${ }^{*}$ Nutrition and Bromatology Group, Analytical and Food Chemistry Department, Faculty of Food Science and Technology, Ourense \\ Campus, University of Vigo, E-32004 Ourense, Spain \\ ${ }^{\S}$ Bodegas Roda, E-26200 Haro, La Rioja, Spain
}

ABSTRACT: The relationship between the proanthocyanidin profile and the perceived astringency was assessed in 13 commercial Tempranillo red wines. The concentration and compositional information were obtained by liquid chromatography with diode array detection coupled to electrospray ionization mass spectrometry after acid-catalyzed depolymerization of wine proanthocyanidins in the presence of excess phloroglucinol. Statistical analysis of the results showed significant correlations between sensory and chemical determinations. Astringency was more affected by the subunit composition than by the total concentration or the average degree of polymerization of wine proanthocyanidins. Higher proportions of epicatechin (EC) subunits in extension positions and gallocatechin (GC) subunits in terminal positions were shown to increase astringency. On the contrary, the amount of epigallocatechin (EGC) in both extension and terminal positions was negatively correlated with the perceived astringency.

KEYWORDS: astringency, wine, flavanol, proanthocyanidins, tannins, phloroglucinol

\section{INTRODUCTION}

Astringency is considered one of the most important sensory attributes of red wines, playing an important role in its overall quality. ${ }^{1,2}$ This property is defined as a complex group of sensations characterized by drying-out, roughing, and puckering of mouth epithelium. ${ }^{3}$

Although the exact mechanisms are not well understood, astringency is thought to mainly result from the interaction between some phenolic compounds and a class of salivary proteins called proline-rich proteins (PRPs). ${ }^{4}$ The subsequent aggregation and precipitation of the resulting complexes have been shown to reduce the lubricity of saliva, increasing friction between oral surfaces. $^{5-7}$

In red wines, the perception of astringency has been mainly attributed to proanthocyanidins (PAs), also known as condensed tannins. Furthermore, these compounds are involved in copigmentation processes with the anthocyanins and the formation of new pigments, which contribute to the stability and definition of red wine color. 8,9

PAs are oligomeric and polymeric flavonoids composed of flavan-3-ol subunits linked by $\mathrm{C}-\mathrm{C}$ bonds. They are widespread throughout the plant kingdom, where they accumulate in many different organs and tissues, providing protection against pathogens and acting as predator repellents. ${ }^{10,11}$ Wine PAs are mainly extracted into wine from the grape skins and seeds during the winemaking process. ${ }^{12,13}$

Seed PAs are composed of $(+)$-catechin $(C),(-)$-epicatechin (EC), and (-)-epicatechin-3-O-gallate subunits. ${ }^{14}$ Because they release cyanidin when they are heated in acidic media, they are also known as procyanidins. Skin PAs differ from seed PAs by the presence of prodelphinidins, since they also contain (+)-gallocatechin, (-)-epigallocatechin (EGC), and (-)-epigallocatechin 3-O-gallate (EGCg) subunits in their structure. In addition, skin PAs show a higher degree of polymerization and a lower proportion of galloylated subunits than seed PAs. ${ }^{15}$

Several papers suggest that PAs are responsible for wine astringency, 1,4 although, to date, a direct link between the presence of PAs in wine and the perceived astringency has not been conclusively shown. In addition to their concentration, the molecular size and composition of PAs seem to be closely related to the astringency. ${ }^{16-18} \mathrm{~A}$ challenging area of research is the potential of PA determination to predict wine astringency, which demands a detailed knowledge of the PA composition as well as the elucidation of the molecular mechanisms involved in the development of astringent sensations. The complexity of polymeric PAs and the lack of commercial pure standards make their analysis a difficult task. ${ }^{19}$ Although reversed-phase highperformance liquid chromatography (RP-HPLC) has been demonstrated to be a powerful technique for the separation of lower molecular weight PAs, larger polymers coelute as a broad unresolved hump. ${ }^{20}$

Acid-catalyzed depolymerization in the presence of nucleophile compounds, such as phloroglucinol ( $\mathrm{Ph}$ ) or benzyl mercaptan, followed by HPLC analysis is a useful alternative for quantification and characterization of larger PAs. ${ }^{21,22}$ This reaction releases the terminal subunits as flavan-3-ol monomers and the extension subunits as adducts of flavan-3-ols with the

Received: May 30, 2012

Revised: November 22, 2012

Accepted: November 26, 2012

Published: November 26, 2012 
corresponding nucleophilic compound. In this way, the composition of PAs can be determined, and several valuable parameters readily can be calculated, such as the average degree of polymerization ( $\mathrm{aDP}$ ) and the percentage of prodelphinidins and galloylated subunits, among others.

The aim of the present work was to study the relationship between the PA composition and the perceived astringency in Spanish red wines using sensory and chemical analyses. PAs characterization was carried out by acid-catalyzed depolymerization in the presence of $\mathrm{Ph}$ followed by liquid chromatography with diode array detector coupled to electrospray ionization mass spectrometry (HPLC-DAD/ESI-MS). The influence of PAs concentration and composition on the wine astringency was statistically assessed through multiple linear regression (MLR) and cluster analysis.

\section{MATERIALS AND METHODS}

Reagents and Standards. All solvents were HPLC grade, and all chemicals were analytical reagent grade. Acetonitrile, acetone, methanol, hydrochloric acid (37\%), acetic acid (100\%), formic acid (98-100\%), sodium acetate ( $\geq 99 \%)$, and sodium bisulfite $(\geq 99 \%)$ were purchased from Merck (Darmstadt, Germany). Ultrapure water was obtained from a Milli-Q Gradient water purification system (Millipore, Bedford, MA).

C, EC, (-)-gallocatechin (GC), Ph, and L-ascorbic acid (AA) were purchased from Sigma-Aldrich (St. Louis, MO). EGC, (-)-epicatechin 3-O-gallate (ECg), and EGCg were supplied by Extrasynthese (Genay, France).

Individual stock solutions of each analyte and a mixture of them were prepared in methanol. Different working standard solutions were made by appropriate dilution in $2.5 \%$ acetic acid in water and then stored in amber glass vials at $-20{ }^{\circ} \mathrm{C}$.

Wine Samples. Thirteen commercial red wines from the Spanish Protected Designations of Origin (PDOs) "Rioja", "Ribera del Duero", and "Toro" were employed over the course of this study (Table 1). They were elaborated with grapes of Vitis vinifera L. cv. Tempranillo variety from vintages ranging from 2006 to 2010 . One of them (R2) consisted of a blend of $96 \%$ Tempranillo and $4 \%$ Graciano. Wines

Table 1. Grape Cultivar, Vintage, PDO, and SensoryDetermined Astringency of the Selected Red Wines

\begin{tabular}{|c|c|c|c|c|}
\hline wines & V. vinifera L. cv. & vintage & PDO & astringency $^{a}$ \\
\hline $\mathrm{T} 1$ & Tempranillo & 2006 & Toro & $1.80 \pm 0.45$ \\
\hline $\mathrm{R} 1$ & Tempranillo & 2008 & Rioja & $1.86 \pm 0.65$ \\
\hline $\mathrm{R} 2$ & $\begin{array}{l}\text { 96\% Tempranillo, } 4 \% \\
\text { Graciano }\end{array}$ & 2008 & Rioja & $0.60 \pm 0.32$ \\
\hline $\mathrm{R} 3$ & Tempranillo & 2009 & Rioja & $3.43 \pm 0.45$ \\
\hline $\mathrm{R} 4$ & Tempranillo & 2010 & Rioja & $3.00 \pm 0.58$ \\
\hline D1 & Tempranillo & 2008 & $\begin{array}{l}\text { Ribera del } \\
\text { Duero }\end{array}$ & $2.60 \pm 0.55$ \\
\hline D2 & Tempranillo & 2008 & $\begin{array}{l}\text { Ribera del } \\
\text { Duero }\end{array}$ & $2.71 \pm 0.81$ \\
\hline D3 & Tempranillo & 2008 & $\begin{array}{l}\text { Ribera del } \\
\text { Duero }\end{array}$ & $2.00 \pm 0.71$ \\
\hline D4 & Tempranillo & 2008 & $\begin{array}{l}\text { Ribera del } \\
\text { Duero }\end{array}$ & $1.93 \pm 0.59$ \\
\hline D5 & Tempranillo & 2009 & $\begin{array}{l}\text { Ribera del } \\
\text { Duero }\end{array}$ & $3.43 \pm 0.45$ \\
\hline D6 & Tempranillo & 2010 & $\begin{array}{l}\text { Ribera del } \\
\text { Duero }\end{array}$ & $3.21 \pm 0.49$ \\
\hline D7 & Tempranillo & 2008 & $\begin{array}{l}\text { Ribera de } \\
\text { Duero }\end{array}$ & $4.40 \pm 0.55$ \\
\hline D8 & Tempranillo & 2008 & $\begin{array}{l}\text { Ribera de } \\
\text { Duero }\end{array}$ & $3.00 \pm 0.71$ \\
\hline
\end{tabular}

${ }^{a}$ Astringency scale from 0 (absence of astringency) to 5 (extreme astringency). were stored under cellar conditions, and all sensory and chemical analyses were carried out by July, 2011. $\mathrm{pH}$ and ethanol values were similar across wines: $\mathrm{pH}$ values were ca. 3.7 , and the ethanol content was ca. $14 \%$. For this reason, they were not included in the statistical model.

PA Extraction. Bleaching of anthocyanins pigments was carried out as described by Alcalde-Eon et al. ${ }^{23}$ with slight modifications. In brief, $2 \mathrm{~mL}$ of wine was adjusted to $\mathrm{pH} 1.0$ with a drop of concentrated hydrochloric acid, transferred to a $5 \mathrm{~mL}$ test tube containing $800 \mathrm{mg}$ of sodium bisulfite, and stirred for $20 \mathrm{~min}$. Under these conditions, most monomeric anthocyanins are combined with bisulfite to form colorless sulfonic acid adducts.

After bleaching, these compounds can be readily retained by anion exchange sorbents. Thus, the bleached wine was diluted 1:1 with ultrapure water, and $2 \mathrm{~mL}$ was loaded into a mixed-mode anion exchange/reversed phase SPE cartridge Oasis MAX $(60 \mathrm{mg}, 3 \mathrm{~mL})$ from Waters (Milford, MA), previously conditioned with $2 \mathrm{~mL}$ of $75 \%$ acetone in water followed by $4 \mathrm{~mL}$ of water. After it was washed with 4 $\mathrm{mL}$ of water, flavan-3-ols and PAs were eluted with $8 \mathrm{~mL}$ of $75 \%$ acetone in water, whereas anthocyanins and organic acids were still retained through anion exchange interactions. The eluate was brought to dryness on a rotary evaporator at $30^{\circ} \mathrm{C}$ and then reconstituted in $200 \mu \mathrm{L}$ of methanol to obtain the methanolic wine extract. To quantify flavan-3-ols in wine, $50 \mu \mathrm{L}$ of this methanolic extract was filled up to 1 $\mathrm{mL}$ with $2.5 \%$ acetic acid in water, filtered by $0.20 \mu \mathrm{m}$, and analyzed by HPLC-DAD/ESI/MS.

Acid-Catalyzed Degradation in the Presence of Ph. PAs extracted from wines were characterized following the acid-catalyzed cleavage of the polymers in the presence of $\mathrm{Ph}$ excess according to the procedure described by Kennedy and Jones ${ }^{22}$ with minor modifications, as follows. A solution containing $0.2 \mathrm{M} \mathrm{HCl}, 50 \mathrm{mg}$ $\mathrm{mL}^{-1} \mathrm{Ph}$, and $10 \mathrm{mg} \mathrm{mL}^{-1} \mathrm{AA}$ was prepared in methanol as phloroglucinolysis reagent. One hundred microliters of methanolic wine extract was allowed to react with $200 \mu \mathrm{L}$ of $\mathrm{Ph}$ solution in a preheated water bath at $50{ }^{\circ} \mathrm{C}$ for $40 \mathrm{~min}$. Afterward, the reaction was cooled down and quenched by the addition of $2.7 \mathrm{~mL}$ of $15 \mathrm{mM}$ sodium acetate aqueous solution. The yield of the phloroglucinolysis reaction was verified by checking the presence of proanthocyanindins by mass spectrometry in all of the phloroglucinolysis reaction extracts. They were not detected, even in trace amounts, and only the phloroglucinolysis adducts and the monomers corresponding to the initiation units were present in the resulting extracts. Therefore, the reaction yield was considered as quantitative. The optimized conditions were also checked with a standard of procyanidin B2, obtaining a conversion yield of $99 \pm 2 \%$. The reaction mixture was purified by SPE using an Oasis MAX cartridge $(60 \mathrm{mg}, 3 \mathrm{~mL})$ previously conditioned with $2 \mathrm{~mL}$ of $75 \%$ acetone in water followed by $4 \mathrm{~mL}$ of water.

The cartridge was washed with $4 \mathrm{~mL}$ of water, and the phloroglucinolysis products were eluted with $8 \mathrm{~mL}$ of $75 \%$ acetone in water. The excess of AA was retained in the cartridge, and an improvement of the chromatographic resolution in the subsequent analysis was obtained. The lack of loss of monomers in SPE had been previously checked through standard addition of catechin and gallocatechin to wine samples. No significant losses of these monomers were detected. The eluate was evaporated to dryness on a rotary evaporator at $30{ }^{\circ} \mathrm{C}$, reconstituted in $1 \mathrm{~mL}$ of $2.5 \%$ acetic acid in water, filtered by $0.20 \mu \mathrm{m}$, and analyzed by HPLC-DAD/ESI/MS.

HPLC-DAD/ESI-MS Analyses. Analyses were carried out in an Agilent 1100 Series HPLC system (Agilent Technologies, Palo Alto, CA) consisting of an autosampler, a quaternary pump, a vacuum degasser, a thermostatted column compartment, and a diode array detector (DAD) and controlled by ChemStation software (version A.05.04; Agilent Technologies). UV/vis spectra were recorded from 200 to $600 \mathrm{~nm}$ while acquiring at a selected wavelength of $280 \mathrm{~nm}$.

Chromatographic separation of the PAs phloroglucinolysis products was performed on a reversed-phase column Spherisorb ODS-2 (150 $\mathrm{mm} \times 4.6 \mathrm{~mm}, 3 \mu \mathrm{m})$ from Waters maintained at $25{ }^{\circ} \mathrm{C}$. Mobile phases $\mathrm{A}$ and $\mathrm{B}$ were, respectively, $0.1 \%$ formic acid in water and acetonitrile. The following linear gradient was used to achieve the 
chromatographic separation: hold at $100 \%$ A for $2 \mathrm{~min}$, decreased to $90 \%$ A over 23 min, and hold for 2 min, decreased to $80 \%$ A over 20 min, decreased to $60 \% \mathrm{~A}$ over $10 \mathrm{~min}$, and hold for $3 \mathrm{~min}$, decreased to $40 \% \mathrm{~A}$ over $5 \mathrm{~min}$ and decreased to $20 \% \mathrm{~A}$ over $5 \mathrm{~min}$, then returned to initial conditions over $5 \mathrm{~min}$ and re-equilibrated for $3 \mathrm{~min}$. The flow rate and the injection volume were set at $0.5 \mathrm{~mL} \mathrm{~min}^{-1}$ and $100 \mu \mathrm{L}$, respectively.

The HPLC system was coupled to a hybrid triple quadrupole/linear ion trap (QqLIT) mass spectrometer API 3200 QTrap (Applied Biosystems, Foster City, CA) equipped with a Turbo V ionization source and controlled by Analyst software (version 1.5; Applied Biosystems).

The mass spectrometer was operated in the negative electrospray ionization (ESI) mode under the following specific conditions: ion spray voltage (IS), $-3700 \mathrm{~V}$; source temperature (TEM), $400{ }^{\circ} \mathrm{C}$; curtain gas (CUR), 20 arbitrary units; ion source gas 1 (GS1), 40 arbitrary units; ion source gas 2 (GS2), 30 arbitrary units; declustering potential (DP), $-25 \mathrm{~V}$; entrance potential $(\mathrm{EP}),-10 \mathrm{~V}$; cell exit potential (CXP), $-3 \mathrm{~V}$; and collision energy (CE), $-20 \mathrm{eV}$. Nitrogen (>99.98\%) was employed as the curtain, ion source, and collision gas. The detection was accomplished in the enhanced MS (EMS) full-scan mode, from $\mathrm{m} / z 100$ to 1700 , and in the enhanced product ion (EPI) mode to obtain the corresponding full-scan MS/MS spectra.

Terminal subunits, that is, flavan-3-ols, were quantified using their corresponding calibration curves obtained at $280 \mathrm{~nm}$. The linearity of the method was tested using standard solutions at six concentration levels from 0.400 to $100 \mu \mathrm{g} \mathrm{mL}^{-1}$ for all compounds except for $\mathrm{ECg}$, which was assessed from 0.200 to $50 \mu \mathrm{g} \mathrm{mL}^{-1}$. Calibration curves were found to be linear in the studied ranges with determination coefficients $\left(R^{2}\right) \geq 0.9989$ and $\operatorname{RSD}(n=3) \leq 6 \%$.

Because of the lack of the corresponding standards, extension subunits, that is, flavan-3-ols $\mathrm{Ph}$ adducts, were quantified using their molar response factors relative to catechin as reported by Kennedy and Jones. ${ }^{22}$ Anyway, the presence of the $\mathrm{Ph}$ adducts was confirmed by mass spectrometry. The mass spectrum of the EGC $\mathrm{Ph}$ adduct obtained in the ESI negative mode exhibited a $[\mathrm{M}-\mathrm{H}]^{-}$ion at $\mathrm{m} / z$ 429 and a $[2 \mathrm{M}-\mathrm{H}]^{-}$ion at $m / z 859$. MS/MS fragmentation of $m / z$ 429 produced a daughter ion at $m / z 303\left[\mathrm{M}-\mathrm{H}-\mathrm{C}_{6} \mathrm{H}_{6} \mathrm{O}_{3}\right]^{-}$, which was indicative for a loss of $\mathrm{Ph}(126 \mathrm{Da})$ and the retro Diels-Alder (RDA) product at $m / z 261\left[\mathrm{M}-\mathrm{H}-\mathrm{C}_{8} \mathrm{H}_{8} \mathrm{O}_{4}\right]^{-}$. The MS analysis of $\mathrm{C}$ and EC Ph adducts showed a $[\mathrm{M}-\mathrm{H}]^{-}$ion at $m / z 413$ and a $[2 \mathrm{M}$ $-\mathrm{H}]^{-}$ion at $m / z$ 827. MS/MS fragmentation product ions of $m / z$ 413 were detected at $m / z 287\left[\mathrm{M}-\mathrm{H}-\mathrm{C}_{6} \mathrm{H}_{6} \mathrm{O}_{3}\right]^{-}($loss of $\mathrm{Ph}$ ) and at $\mathrm{m} / z 261\left[\mathrm{M}-\mathrm{H}-\mathrm{C}_{8} \mathrm{H}_{8} \mathrm{O}_{3}\right]^{-}$(RDA fission).

Sensory Evaluation. The tasting panel was composed of seven wine professionals, including winemakers and enologists. Panelists were requested to evaluate the astringency of the studied wines on a scale from 0 to 5 , with 0 values being assigned when there was an absolute absence of astringency and an intensity score of 5 representing an extreme astringency. Alum was used as a reference standard. Two of the previous training sessions were conducted to standardize criteria among the panel members. Astringency evaluation was carried out in two different sensory sessions with six and seven wines, respectively. Wines were presented at room temperature in wineglasses randomly coded with three-digit numbers. At the end of each session, all scorecards were collected, and the average value was calculated (Table 1). To evaluate the consistency of the trained panel, one-way analysis of variance (ANOVA) was carried out with the scores given by them. The variance of the astringency scores is divided in two components, the one related to wine and the other related to panelist. The wine component causes $99.43 \%$ of the astringency variance, while the panelist component causes $0.57 \%$ of variance, supporting the reliability of the sensory panel.

Statistical Data Treatment. Statistical analysis of data was performed through ANOVA (95\% confidence level), stepwise MLR, and cluster analysis (furthest neighbor method, squared Euclidean distance) using the software package Statgraphics Centurion XV (Manugistics, Rockville, MD).

\section{RESULTS AND DISCUSSION}

Flavan-3-ol Monomers Composition. Wine extracts were analyzed before the phloroglucinolysis reaction to quantify the monomeric flavan-3-ols. As shown in Figure 1, the values in

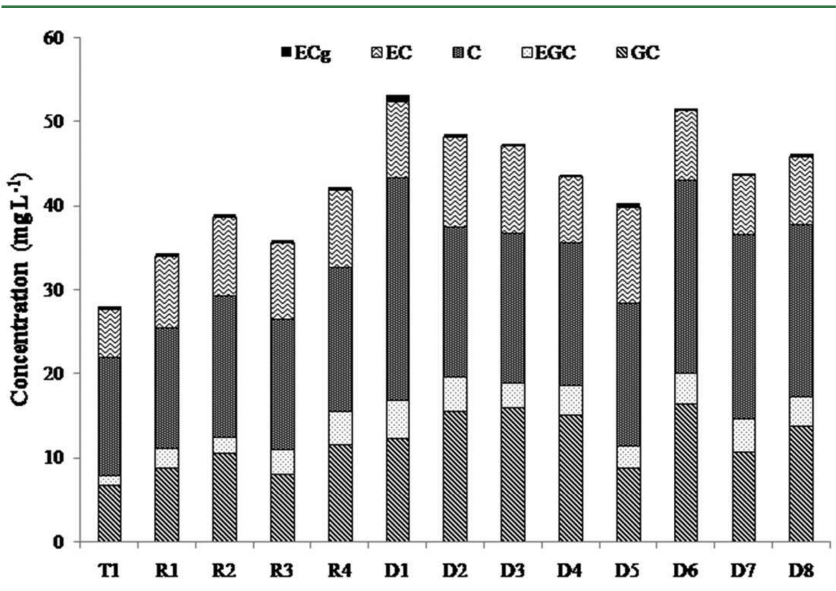

Figure 1. Monomeric flavan-3-ols profiles of the studied red wines.

Rioja wines ranged from 34 to $42 \mathrm{mg} \mathrm{L}^{-1}$, whereas in Ribera del Duero wines, they were slightly higher, varying from 40 to 53 $\mathrm{mg} \mathrm{L}^{-1}$. The only Toro wine in this study, which was also the oldest one, presented the lowest monomers concentration.

Regarding the monomeric composition, $\mathrm{C}$ was the predominant monomeric flavan-3-ol accounting for 37-51\% of the total monomeric content. Important amounts of GC $(22-34 \%)$ and EC (16-28\%) were also presented in all of the wines. The percentages of EGC ranged from 4 to $9 \%$, whereas ECg was found only at trace levels $(<1 \%)$. These flavan-3-ol profiles were in accordance with previously reported values for other Tempranillo wines. ${ }^{13,24,25}$

PA Composition. Acid-catalyzed depolymerization in the presence of $\mathrm{Ph}$ provided valuable information on PA subunit composition, aDP, average molecular weight (aMW), and total PA concentration of these wines (Table 2). The aDP was calculated, as described by Kennedy; ${ }^{26}$ briefly, it is determined by dividing the sum of all PAs subunits (flavan-3-olmonomers and flavanol-3-ol $\mathrm{Ph}$ adducts) to the sum of terminal units (flavan-3-ol monomers), in mole equivalents relative to catechin. The concentrations of flavan-3-ol monomers in wine before the phloroglucinolysis reaction were subtracted from the corresponding concentrations of flavan-3-ols after reaction to determine the terminal subunits. The aMW was estimated based on the proportional composition and the aDP of the PAs. The total PA concentration was calculated as the sum of the individual subunit concentrations. The percentage of prodelphinidins (\% PD) was calculated as the molar sum of terminal and extension subunits of gallocatechin and epigallocatechin divided by the sum of all PAs subunits in mole equivalents.

Regarding the PAs composition, C, EC, GC, EGC, and ECg were found as terminal subunits, whereas only C, EC, and EGC were identified as extension constituents. Among the terminal subunits, C was the predominant monomer (14-20\% of total subunits), followed by EC (5-10\% of total subunits) and GC (1-4\% of total subunits). EGC and ECg were scarcely detected in terminal positions, except for wine D1, which showed $1.6 \%$ of $\mathrm{ECg}$ as terminal subunits. 


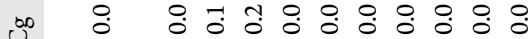
-1 $+1+1+1+1+1+1+1+1+1+$ $\therefore$ 会 ن

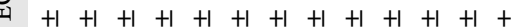

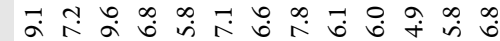
공

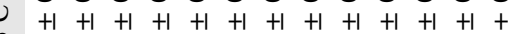

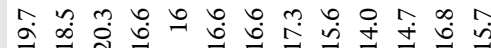

U 동

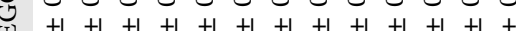

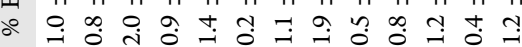

चี 0

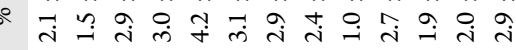

ริำ

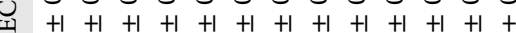

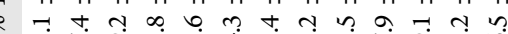

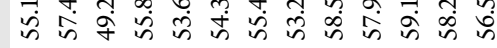

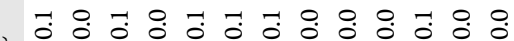

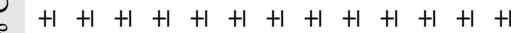

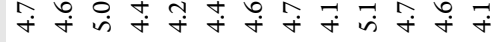

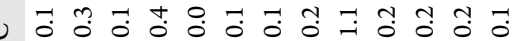
$\begin{aligned} & 0 \\ & 0\end{aligned}+1+1+1+1+1+1+1+1+1+1+1+1$ o

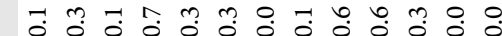
$2+1+1+1+1+1+1+1+1+1+1+1+1$ 足

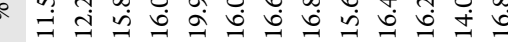

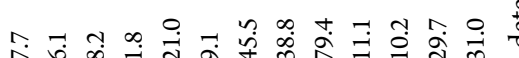
$3+1+1+1+1+1+1+1+1+1+1+1+1+1$

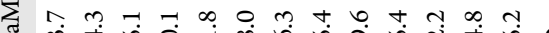

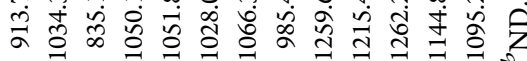
$\therefore \circ: 00$ 웅
EC was the major extension constituent accounting for between 49 and $59 \%$ of total subunits. Extension subunits also contained an important proportion of EGC (8-14\% of total subunits) and C (4-5\% of total subunits). Thus, the percentage of prodelphinidin subunits ranged from $11 \%$ for wine $\mathrm{T} 1$ to $20 \%$ for the wine $\mathrm{R} 4$.

The observed composition of wine PAs resembled the profile of skins PAs more than that of seeds, mainly due to the presence of significant proportions of prodelphinidin subunits (GC and EGC) as well as the reduced content of galloylated subunits. ${ }^{15}$ Concerning the aDP, values were quite similar for all wines varying from 2.9 to 4.3 , which indicated that trimers and tetramers might be the predominant polymeric PAs. These results were in accordance with those reported in wines from other grape varieties, ${ }^{27-31}$ and they were also comparable to those obtained by Gonzalez-Manzano et al..$^{32}$ in Tempranillo and Graciano wines. Nevertheless, the obtained aDP values were in disagreement with those reported by Monagas et al. ${ }^{25}$ for a Tempranillo wine with an aDP of 13 . However, these authors carried out a previous fractionation of wine, so the reported aDP was only referred to the most polymeric fraction of wine.

As can be seen in Table 2, the total concentration of PAs ranged from 351 to $1314 \mathrm{mg} \mathrm{L}^{-1}$. Once again, the lowest content of PAs was obtained in the wine from the oldest vintage (T1). Concentration values for the Rioja wines varied from 408 to $953 \mathrm{mg} \mathrm{L}^{-1}$, whereas Ribera del Duero wines were slightly higher, in the range of $608-1314 \mathrm{mg} \mathrm{L}^{-1}$.

Multivariate Analysis of Perceived Astringency. Once we obtained the monomeric flavan-3-ols and the PA compositions of the studied wines, multivariate methodologies were employed in an attempt to describe the existent relationship between the sensory-determined astringency (Table 1) and the flavanolic composition.

Earlier studies have suggested a positive relationship between astringency and PAs concentration. ${ }^{18,33-35}$ Nevertheless, in our study (range of concentrations of PAs, $351-1314 \mathrm{mg} \mathrm{L}^{-1}$ ), the total concentration of PAs did not show statistical correlation with the perceived astringency, explaining only about $40 \%$ of variability of the sensory values (data not shown). MLR was performed to evaluate the influence of main compositional parameters on the perceived astringency. Astringency was selected as the dependent variable, whereas monomeric flavan3-ols concentrations, PA subunits concentrations, and aDP were used as independent variables. MLR was conducted applying a backward-stepwise strategy, which involves starting with all considered variables and removing the least significant one at each step of the process. The model is refitted after each step including only the most significant variables. Among all initially considered variables, only four were statistically significant $(p<0.05)$ in the final model, and they are shown in Table 3, namely, concentrations of EC and EGC in extension positions and GC and EGC in terminal positions.

The coefficient of determination $\left(R^{2}=0.877\right)$ indicated that the proposed model explained $87.7 \%$ of the variability observed in the astringency, which supposed a quite good fit to the data. A further illustration of this fit can be observed in Figure 2 with the relationship between observed and predicted astringency. As shown, the fitted model makes it possible to obtain a good linear correlation with observed data.

Monomeric flavan-3-ols concentrations were not significant for wine astringency, so they were removed from the model at the initial steps of the regression. This result was in agreement 
Table 3. Results of the MLR Analysis for the Perceived Astringency ${ }^{a}$

$\begin{array}{lclrl}\text { parameter } & \text { regression coefficient } & \text { standard error } & t \text { statistic } & p \text { value } \\ \text { constant } & -2.57212 & 1.54559 & -1.66417 & 0.1117^{b} \\ \text { [GCt] } & 0.0828023 & 0.0270845 & 3.05718 & 0.0062 \\ \text { [ECe] } & 0.012017 & 0.00238026 & 5.04862 & 0.0001 \\ \text { [EGCe] } & -0.0435143 & 0.0170423 & -2.55332 & 0.0189 \\ \text { [EGCt] } & -0.0732321 & 0.0298481 & -2.45349 & 0.0234\end{array}$

${ }^{a}$ Abbreviations: GCt, GC in terminal positions; ECe, EC in extension positions; EGCe, EGC in extension positions; and EGCt, EGC in terminal positions. ${ }^{b}$ Nonsignificant $(p \geq 0.05)$.

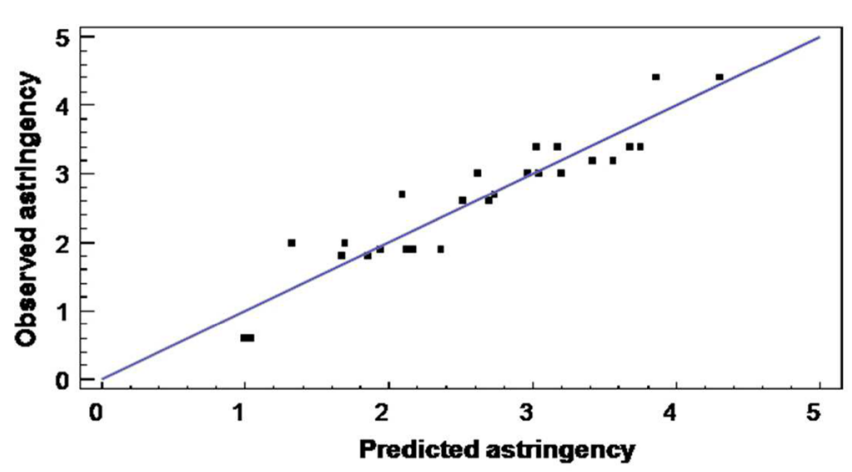

Figure 2. Observed vs predicted plot for the astringency of the studied red wines.

with previous studies where wine astringency was attributed to the PAs more than the monomeric flavan-3-ols. ${ }^{17,36}$ The molecular size of PAs, and consequently their aDP, is generally believed to affect the sensory properties of wine. ${ }^{8,18,31}$ According to our results, the aDP of the PAs was not statistically correlated with the perceived astringency, although it was close to the signification level $(p$ value $=0.0834)$. It has been reported that an increase in the molecular size of PAs leads to an increase in the perceived astringency, ${ }^{17}$ although this behavior was observed at equal concentrations of PAs and for important differences in the aDP. In the present study, the degrees of polymerization of PAs varied from 2.9 to 4.3 (Table 2 ), suggesting that within this range, wine astringency might be mainly due to others factors such as PAs subunit concentration and composition. Canals et al. ${ }^{29}$ reported for several red wines showing similar aDPs and composition that the total concentration was the major determinant of astringency. Nevertheless, as it has been previously indicated, in our study, the total concentration of PAs explains only about $40 \%$ of the perceived astringency.

According to the fitted regression model, the concentration of EC monomeric subunits in extension positions was the most significant factor in the obtained model (Table 3), showing an important positive correlation with the perceived astringency. Thus, the higher the concentration of EC in these positions, the more astringent the wine.

Regarding the influence of prodelphinidins, similar strength but opposed effects were observed between GC and EGC constitutive subunits (Table 3). Whereas the concentration of GC subunits in terminal positions of PAs was positively correlated with the astringency, an increase in the concentration of EGC in both terminal and extensions positions reduced the perceived astringency. Vidal et al. ${ }^{18}$ reported that in a winelike medium, the presence of EGC units in the PAs could decrease the coarse perception. Recently, Fernandez et al. ${ }^{37}$ also observed that although Carmenere wines had a higher PAs concentration and aDP than Cabernet Sauvignon wines, and the former wines were perceived as less astringent than the latter. This fact was attributed to the higher proportion of EGC in Carmenere as compared with Cabernet Sauvignon wines.

Although galloylation has been previously suggested to increase PA affinity toward salivary proteins, ${ }^{38,39}$ the concentration of ECg subunits was not statistically significant for the astringency in the present study, probably related to the low levels of galloylated compounds detected in the studied wines.

The phenomenon of astringency has been mainly attributed to salivary protein precipitation that leads to reduced lubricating properties of saliva and to increased friction between mouth surfaces. The present results suggested that the interactions responsible for the astringent sensations are significantly affected by the stereochemistry and the conformational preferences of PAs. Previous studies have also shown that astringency may be modulated by accessibility of interaction sites and molecular conformation. ${ }^{40-43}$

In a second stage of the statistical evaluation, cluster analysis was carried out to assess whether the differences in the PAs composition enable us to group the wines according to their perceived astringency. Cluster analysis is an exploratory data analysis tool that aims at sorting different objects into groups in a way that the similarity between two objects is maximal if they belong to the same group and minimal otherwise. The squared Euclidean distance was taken as measure of the similarity between the different samples, and the furthest neighbor method algorithm was used to group the samples. Only those compositional variables that previously resulted in significance in the MLR were considered in the cluster analysis. No data on the astringency were supplied for this analysis. The results of the cluster analysis are displayed as a dendrogram in Figure 3.

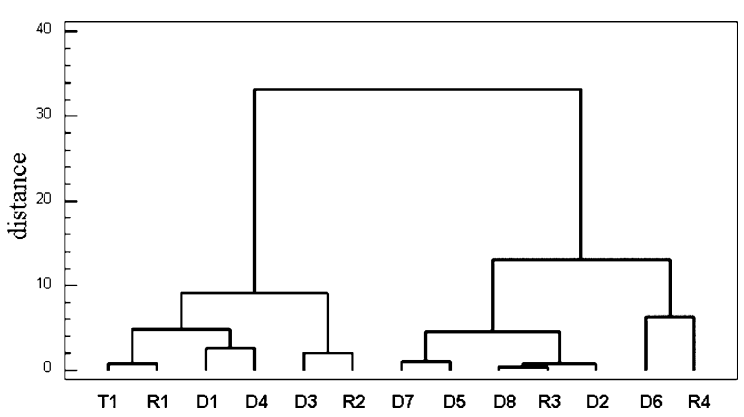

Figure 3. Dendrogram obtained from the cluster analysis.

From the bottom up, the dendrogram shows the sequence of joins that were made between clusters. Lines are drawn connecting the clustered that are joined at each step, while the vertical axis displays the distance between the clusters when they were joined.

The general shape of the dendrogram suggested grouping the wines into two main clusters, at a distance of approximately 33 units. One of them included wines T1, R1, R2, D1, D3, and D4, whereas the other one was composed of wines R3, R4, D2, D5, D6, D7, and D8. It can be observed that the cluster analysis enabled us to roughly group all wines according to their astringency. As shown in Table 1, wines in the first main cluster showed the lowest astringency values, ranging from $0.60 \pm 0.32$ to $2.60 \pm 0.55$, whereas the second cluster grouped the wines with the highest astringencies, varying from $2.71 \pm 0.81$ to 4.4 \pm 0.55 . Therefore, this analysis allowed the formation of two 
clusters according to the astringency although astringency data were not included in the model. According to data in Table 2, the variations between the two clusters were in both the total content and the composition of PAs.

These clusters consisted of various small subgroups of wines showing similar PAs compositions taking into account all of the subunits determinate in the study. For instance, wines D8 and R3 were clustered within a very short distance $(0.3)$, indicating a high similarity degree regarding their PAs profiles. The astringency scores for these wines were 3.00 and 3.43, respectively, indicating that other factors than the flavanolic composition (e.g., flavonol composition, phenolic acids, and polysaccharide composition) may also contribute to the perception.

It was also observed that all wines belonging to the first main cluster and therefore, with the lowest astringency values, were from the oldest vintages (2006 and 2008). Furthermore, the only two wines from the 2010 vintage were linked together in the second cluster, at a distance of approximately 6 . No clustering was observed with the PDOs of studied wines, probably due to the fact that all of them were made of the same grape variety Tempranillo. These results were in good agreement with those previously obtained from MLR, showing the potential of the selected parameters for the prediction of red wines astringency.

In conclusion, statistical analysis of the results showed significant correlations between the global intensity of the astringency and the structural characteristics of the PAs (subunit composition). Higher proportions of EC subunits in extension positions and GC subunits in terminal positions were shown to increase astringency. On the other hand, the amount of EGC in both extension and terminal positions was negatively correlated with the perceived astringency. Contrary to what is commonly considered, the total concentration of PAs did not show statistical correlation with the perceived astringency. The analysis of the content of the aforementioned subunits seems to have a good potential for the prediction of red wines astringency, although a comprehensive study with a higher number of wine samples including different varieties, regions, etc., is necessary to develop predictive models in the future.

\section{AUTHOR INFORMATION}

\section{Corresponding Author}

*Tel: +34 923294537. Fax: +34 923294515. E-mail: escriban@ usal.es.

\section{Funding}

Thanks are due to the Spanish MINECO for financial support (Project ref AGL2011-30254-C02-01). J.R. and N.Q.M. acknowledge the Ministerio de Ciencia e Innovación of Spain (MICINN) for his Juan de la Cierva contract and for her FPIscholarship, respectively.

\section{Notes}

The authors declare no competing financial interest.

\section{REFERENCES}

(1) Gawel, R. Red wine astringency: A review. Aust. J. Grape Wine Res. 1998, 4 (2), 74-95.

(2) Jackson, R. S. Wine Tasting: A Professional Handbook; Elsevier Academic Press: San Diego, CA, 2002.

(3) ASTM. Standard Definitions of Terms Relating to Sensory Evaluation of Materials and Products; American Society for Testing and Materials; Philadelphia, PA, 2004.
(4) McRae, J. M.; Kennedy, J. A. Wine and Grape Tannin Interactions with Salivary Proteins and Their Impact on Astringency: A Review of Current Research. Molecules 2011, 16 (3), 2348-2364.

(5) Baxter, N. J.; Lilley, T. H.; Haslam, E.; Williamson, M. P. Multiple Interactions between Polyphenols and a Salivary Proline-Rich Protein Repeat Result in Complexation and Precipitation. Biochemistry 1997, 36 (18), 5566-5577.

(6) Jöbstl, E.; O'Connell, J.; Fairclough, J. P. A.; Williamson, M. P. Molecular Model for Astringency Produced by Polyphenol/Protein Interactions. Biomacromolecules 2004, 5 (3), 942-949.

(7) Soares, S.; Vitorino, R.; Osório, H.; Fernandes, A.; Venâncio, A.; Mateus, N.; Amado, F.; de Freitas, V. Reactivity of Human Salivary Proteins Families Toward Food Polyphenols. J. Agric. Food Chem. 2011, 59 (10), 5535-5547.

(8) Cheynier, V.; Dueñas-Paton, M.; Salas, E.; Maury, C.; Souquet, J.M.; Sarni-Manchado, P.; Fulcrand, H. Structure and Properties of Wine Pigments and Tannins. Am. J. Enol. Vitic. 2006, 57 (3), 298-305.

(9) González-Manzano, S.; Dueñas, M.; Rivas-Gonzalo, J. C.; Escribano-Bailón, M. T.; Santos-Buelga, C. Studies on the copigmentation between anthocyanins and flavan-3-ols and their influence in the colour expression of red wine. Food Chem. 2009, 114 (2), 649-656.

(10) Dixon, R. A.; Xie, D.-Y.; Sharma, S. B. Proanthocyanidins-A final frontier in flavonoid research? New Phytol. 2005, 165 (1), 9-28.

(11) Treutter, D. Significance of flavonoids in plant resistance: A review. Environ. Chem. Lett. 2006, 4 (3), 147-157.

(12) Brossaud, F.; Cheynier, V.; Noble, A. C. Bitterness and astringency of grape and wine polyphenols. Aust. J. Grape Wine Res. 2001, 7 (1), 33-39.

(13) González-Manzano, S.; Rivas-Gonzalo, J. C.; Santos-Buelga, C. Extraction of flavan-3-ols from grape seed and skin into wine using simulated maceration. Anal. Chim. Acta 2004, 513 (1), 283-289.

(14) Prieur, C.; Rigaud, J.; Cheynier, V.; Moutounet, M. Oligomeric and polymeric procyanidins from grape seeds. Phytochemistry 1994, 36 (3), $781-784$.

(15) Souquet, J.-M.; Cheynier, V.; Brossaud, F.; Moutounet, M. Polymeric proanthocyanidins from grape skins. Phytochemistry 1996, 43 (2), 509-512.

(16) Peleg, H.; Gacon, K.; Schlich, P.; Noble, A. C. Bitterness and astringency of flavan-3-ol monomers, dimers and trimers. J. Sci. Food Agric. 1999, 79 (8), 1123-1128.

(17) Vidal, S.; Francis, L.; Guyot, S.; Marnet, N.; Kwiatkowski, M.; Gawel, R.; Cheynier, V.; Waters, E. J. The mouth-feel properties of grape and apple proanthocyanidins in a wine-like medium. J. Sci. Food Agric. 2003, 83 (6), 564-573.

(18) Gawel, R.; Francis, L.; Waters, E. J. Statistical Correlations between the In-Mouth Textural Characteristics and the Chemical Composition of Shiraz Wines. J. Agric. Food Chem. 2007, 55 (7), 2683-2687.

(19) Hümmer, W.; Schreier, P. Analysis of proanthocyanidins. Mol. Nutr. Food Res. 2008, 52 (12), 1381-1398.

(20) Guyot, S.; Doco, T.; Souquet, J.-M.; Moutounet, M.; Drilleau, J.F. Characterization of highly polymerized procyanidins in cider apple (Malus sylvestris var. kermerrien) skin and pulp. Phytochemistry 1997, 44 (2), 351-357.

(21) Matthews, S.; Mila, I.; Scalbert, A.; Pollet, B.; Lapierre, C.; Hervé du Penhoat, C. L. M.; Rolando, C.; Donnelly, D. M. X. Method for Estimation of Proanthocyanidins Based on Their Acid Depolymerization in the Presence of Nucleophiles. J. Agric. Food Chem. 1997, 45 (4), 1195-1201.

(22) Kennedy, J. A.; Jones, G. P. Analysis of Proanthocyanidin Cleavage Products Following Acid-Catalysis in the Presence of Excess Phloroglucinol. J. Agric. Food Chem. 2001, 49 (4), 1740-1746.

(23) Alcalde-Eon, C.; Escribano-Bailón, M. T.; Santos-Buelga, C.; Rivas-Gonzalo, J. C. Separation of pyranoanthocyanins from red wine by column chromatography. Anal. Chim. Acta 2004, 513 (1), 305318.

(24) Monagas, M.; Gómez-Cordovés, C.; Bartolomé, B.; Laureano, O.; Ricardo da Silva, J. M. Monomeric, Oligomeric, and Polymeric 
Flavan-3-ol Composition of Wines and Grapes from Vitis vinifera L. Cv. Graciano, Tempranillo, and Cabernet Sauvignon. J. Agric. Food Chem. 2003, 51 (22), 6475-6481.

(25) García-Marino, M.; Hernández-Hierro, J. M.; Santos-Buelga, C.; Rivas-Gonzalo, J. C.; Escribano-Bailón, M. T. Multivariate analysis of the polyphenol composition of Tempranillo and Graciano red wines. Talanta 2011, 85 (4), 2060-2066.

(26) Kennedy, J. A. Proanthocyanidins: Extraction, Purification, and determination of subunit composition by HPLC. Curr. Protoc. Food Anal. Chem. 2002, 6, I1.4.1-I1.4.11.

(27) Busse-Valverde, N.; Gómez-Plaza, E.; López-Roca, J. M.; GilMuñoz, R; Fernández-Fernández, J. I.; Bautista-Ortín, A. B. Effect of Different Enological Practices on Skin and Seed Proanthocyanidins in Three Varietal Wines. J. Agric. Food Chem. 2010, 58 (21), 1133311339.

(28) Lee, J.; Kennedy, J. A.; Devlin, C.; Redhead, M.; Rennaker, C. Effect of early seed removal during fermentation on proanthocyanidin extraction in red wine: A commercial production example. Food Chem. 2008, 107 (3), 1270-1273.

(29) Canals, R.; del Carmen Llaudy, M.; Canals, J.; Zamora, F. Influence of the elimination and addition of seeds on the colour, phenolic composition and astringency of red wine. Eur. Food Res. Technol. 2008, 226 (5), 1183-1190.

(30) Kontoudakis, N.; Esteruelas, M.; Fort, F.; Canals, J. M.; De Freitas, V.; Zamora, F. Influence of the heterogeneity of grape phenolic maturity on wine composition and quality. Food Chem. 2011, 124 (3), 767-774.

(31) Chira, K.; Pacella, N.; Jourdes, M.; Teissedre, P.-L. Chemical and sensory evaluation of Bordeaux wines (Cabernet-Sauvignon and Merlot) and correlation with wine age. Food Chem. 2011, 126 (4), 1971-1977.

(32) González-Manzano, S.; Santos-Buelga, C.; Pérez-Alonso, J. J.; Rivas-Gonzalo, J. C.; Escribano-Bailón, M. T. Characterization of the Mean Degree of Polymerization of Proanthocyanidins in Red Wines Using Liquid Chromatography-Mass Spectrometry (LC-MS). J. Agric. Food Chem. 2006, 54 (12), 4326-4332.

(33) Kennedy, J. A.; Ferrier, J.; Harbertson, J. F.; des Gachons, C. P. Analysis of Tannins in Red Wine Using Multiple Methods: Correlation with Perceived Astringency. Am. J. Enol. Vitic. 2006, 57 (4), 481-485.

(34) Landon, J. L.; Weller, K.; Harbertson, J. F.; Ross, C. F. Chemical and Sensory Evaluation of Astringency in Washington State Red Wines. Am. J. Enol. Vitic. 2008, 59 (2), 153-158.

(35) Boselli, E.; Boulton, R. B.; Thorngate, J. H.; Frega, N. G. Chemical and Sensory Characterization of DOC Red Wines from Marche (Italy) Related to Vintage and Grape Cultivars. J. Agric. Food Chem. 2004, 52 (12), 3843-3854.

(36) Robichaud, J. L.; Noble, A. C. Astringency and bitterness of selected phenolics in wine. J. Sci. Food Agric. 1990, 53 (3), 343-353.

(37) Fernández, K.; Kennedy, J. A.; Agosin, E. Characterization of Vitis vinifera L. Cv. Carménère Grape and Wine Proanthocyanidins. J. Agric. Food Chem. 2007, 55 (9), 3675-3680.

(38) de Freitas, V.; Mateus, N. Structural Features of Procyanidin Interactions with Salivary Proteins. J. Agric. Food Chem. 2001, 49 (2), 940-945.

(39) Canon, F.; Giuliani, A.; Paté, F.; Sarni-Manchado, P. Ability of a salivary intrinsically unstructured protein to bind different tannin targets revealed by mass spectrometry. Anal. Bioanal. Chem. 2010, 398 (2), 815-822.

(40) Prigent, S. V. E.; Voragen, A. G. J.; van Koningsveld, G. A.; Baron, A.; Renard, C. M. G. C.; Gruppen, H. Interactions between globular proteins and procyanidins of different degrees of polymerization. J. Dairy Sci. 2009, 92 (12), 5843-5853.

(41) Cala, O.; Pinaud, N.; Simon, C.; Fouquet, E.; Laguerre, M.; Dufourc, E. J.; Pianet, I. NMR and molecular modeling of wine tannins binding to saliva proteins: revisiting astringency from molecular and colloidal prospects. FASEB J. 2010, 24 (11), 4281-4290.

(42) Simon, C.; Barathieu, K.; Laguerre, M.; Schmitter, J.-M.; Fouquet, E.; Pianet, I.; Dufourc, E. J. Three-Dimensional Structure and
Dynamics of Wine Tannin-Saliva Protein Complexes. A Multitechnique Approach. Biochemistry 2003, 42 (35), 10385-10395.

(43) McRae, J. M.; Falconer, R. J.; Kennedy, J. A. Thermodynamics of Grape and Wine Tannin Interaction with Polyproline: Implications for Red Wine Astringency. J. Agric. Food Chem. 2010, 58 (23), 1251012518. 